\title{
Behavioural Finance: A Re-Examination of Prospect Theory
}

\author{
Rama Seth*, Bobbur Abhilash Chowdary \\ Department of Finance and Control, Indian Institute of Management Calcutta, Kolkata, India \\ Email: ${ }^{*}$ rama_seth@iimcal.ac.in
}

How to cite this paper: Seth, R. and Chowdary, B.A. (2017) Behavioural Finance: A Re-Examination of Prospect Theory. Theoretical Economics Letters, 7, 11341149.

https://doi.org/10.4236/tel.2017.75077

Received: May 19, 2017

Accepted: July 18, 2017

Published: July 21, 2017

Copyright $\odot 2017$ by authors and Scientific Research Publishing Inc. This work is licensed under the Creative Commons Attribution International License (CC BY 4.0).

http://creativecommons.org/licenses/by/4.0/

\begin{abstract}
Behavioural finance has received a major impetus over the last two decades. In this paper, we discuss the foundations which have helped in this paradigm shift from traditional Efficient Market Hypothesis (EMH) to the more experimental branch of finance, namely behavioural finance. We discuss EMH in the context of its critics, and present alternative theories as well as psychological concepts that are useful in understanding behavioural finance. We conduct 3 separate experiments to test Prospect theory, a popular theory put forth by Kahneman \& Tversky [1]. We conduct the experiments on a different type of respondent group than that has been used in the past. Using a relatively homogenous group well versed in probability and statistics, we find that career professionals exhibit less biases than student subjects that have been used in such experiments in the past.
\end{abstract}

\section{Keywords}

Experimental Economics, Behavioural Finance, Behavioural Economics, Prospect Theory, Experimental Finance, Efficient Market Hypothesis

\section{Introduction}

Behavioural finance is one of the newer upcoming areas in finance which has received a major impetuous over the last two decades. It is a field that seeks to combine behavioural and cognitive psychological theory with conventional economics and finance to provide explanations for why people make irrational financial decisions. Behavioural finance, unlike traditional finance, assumes that there are limits to arbitrage and that all humans are not rational. One of the crude assumptions that traditional theories make is that people are rational and always seek to maximize their own well-being by increasing their wealth. Emotions and other extraneous factors do not influence people when it comes to 
making economic choices. It assumes that even if there are some irrational agents, they will be weeded out of the market through arbitrage. However several studies have shown that there are limits to arbitrage [2], and human emotions and sentiment can affect market outcomes. Behavioral finance seeks to explain "real man" actions, whereas modern finance seeks to explain the actions of an imaginary "economic man" (Homo economicus). Humans are not always rational and neither do they have infinite computing power to consider all the possible situations to make best decisions. In fact, more often than not people use rules of thumb rather than long, laborious calculations which can result in making sub-optimal choices and can create market frictions. Another assumption of traditional theory that irrational market participants are weeded out of the market through arbitrage can also be challenged on many fronts. For example, take the case of a student who makes a wrong decision in joining the university best suitable for his career. There is no way an arbitrage is possible in such situations. Let's take another example of casino gambling. The odds are set such that in the long run all the players only make losses. Still many people gamble every day. If markets were complete and perfect arbitrage was possible, all the gamblers (irrational agents) should have lost all their money to the casinos and casinos should have run out of business which is not the case. Hence it can be argued that markets are not successful in deterring irrational people from entering markets and arbitrage opportunities can persist for long periods of time. Therefore, it is important that we find an alternative theory to explain actions of these irrational agents, which can influence the outcome, while making decisions.

Even though behavioral finance has established itself as a full-fledged branch of research, understanding it requires an understanding of some of the basic principles of Efficient Market Hypothesis (EMH). In what follows, we will start with a discussion of EMH before outlining its problems and the raison d'être of behavioral finance. Hence Section II outlines some of the basic concepts of EMH which are helpful in understanding behavioral finance literature. Section III contains an analytical survey of empirical studies which challenge the assumptions of traditional finance literature.

In Section IV, we discuss various psychological concepts which are widely used in behavioral finance. In section $\mathrm{V}$ we present our experimental results of Prospect theory. Section VI presents the concluding remarks.

\section{Efficient Market Hypothesis: An Introduction}

Efficient Market Hypothesis states that markets always reflect complete information in prices. However, this statement is very general, and it is very difficult to conduct empirical tests to prove or disprove this hypothesis. Fama [3] classified the tests on EMH into three categories based on the information set under consideration. The weak form efficiency in which the information set under consideration is historical prices, the semi-strong form efficiency in which the information set under consideration is all publicly available information, and the 
strong form efficiency in which the information set under consideration is all publicly and privately available information.

\section{(a) The weak form of market efficiency tests}

In the weak form of market efficiency tests the "fair game" variable $\left(Z_{i, t}\right)$, defined as given below, should have zero serial covariance between its lagged values else the market is weak form inefficient.

$$
Z_{i, t}=r_{i, t}-E\left(r_{i, t} \mid r_{i, t-1}, r_{i, t-2}, \cdots\right)
$$

where $r_{i, t}$ refers to stock $i$ in period $t$. This definition implies that the actual stock returns are randomly distributed around an expected mean return. However, this condition is sometimes mistaken to be equivalent to equation 2 which is a necessary condition for random walk models.

$$
E\left(r_{i, t+1} \mid r_{i, t}\right)=E\left(r_{i, t+1}\right)
$$

Random walk models assume that expected stock returns are constant and do not vary over time as implied in Equation (2). However, this is not a necessary condition for markets to be efficient. If the stock returns follow a random walk, then they are weak form efficient. On the contrary, if the stock returns are weak form efficient they need not follow a random walk. The expected returns in the above equations can be estimated using any model (e.g. Sharpe-Linter model etc).

Another way of testing weak form of EMH is to see if any trading rule formed using past returns data can generate excess profits. The final method of disproving weak form of market efficiency hypothesis would be to show that some of the market microstructure related constructs can lead to inefficiency.

\section{(b) The semi-strong form of market efficiency tests}

The semi-strong form of market efficiency says that the stock prices fully reflect all the publicly available information. A lot of publicly available information is subjective and can be interpreted in different ways by different people. Whatever be the price of the security it can always be justified as a result of careful consideration of all the publicly available information. Hence it is very difficult to directly test if the stock prices actually reflect all the information. The best way to test semi-strong form of efficiency would be to do an event based study. A lot of event-based studies on stock splits, earnings announcements, etc. have been conducted in this area which will be discussed in greater detail in section III.

\section{(c) The strong form of market efficiency tests}

A considerable amount of research has been done in this area, and there is a general consensus among researchers that markets are not strong form efficient. For example, Niederhoffer \& Osborne [4] have shown that specialists on NYSE use their monopolistic access to information for generating profits. The Enron and WorldCom scandals in the US; Satyam Computers Services scandal in India, etc are glaring examples of strong form of market inefficiency. Since most of the investors do not have access to private information, it is unreasonable to assume that market prices fully reflect private information. Hence for the remainder of 
the paper, we will not discuss strong form tests for market efficiency.

This basic understanding of EMH will be helpful in understanding which type of tests refute (or support) EMH at what level of market efficiency i.e. Strong, Semi-strong or Weak level of market efficiency. An important feature of these tests on EMH is the Joint Hypothesis problem. Most of the tests on EMH must assume the validity of an equilibrium asset pricing model. For example, weak form of market efficiency tests check for zero serial autocorrelation of "fair game" variable $\left(Z_{i, t}\right)$ defined as in equation 1 . Estimating this fair game variable requires estimation of $E\left(r_{i, t} \mid r_{i, t-1}, r_{i, t-2}, \cdots\right)$ which represents next period's expected return conditional on past returns. This next period expected return conditional on past returns is generally estimated using an equilibrium asset pricing model like CAPM, Fama-French three factor model etc. Similarly, event based studies in semi-strong form of market efficiency tests assume the validity of an equilibrium asset pricing model for calculating risk adjusted excess returns.

Therefore, every such test on market efficiency is a dual test of both market efficiency and the equilibrium pricing model. So, if any of these tests reject EMH it could be either due to the deficiencies in the equilibrium pricing model or because the markets are inefficient or both. This is called the joint hypothesis problem and one of the prime reasons behind the difficulties in disproving EMH. With this understanding, we now provide an analytical review of literature discrediting EMH in the next section.

\section{Analytical Review of Literature Discrediting Traditional Theory}

The literature in behavioral finance is continuously evolving with new branches developing every day. In what follows, we divide the entire literature into four categories. The first group covers studies related to the Capital Asset Pricing Model. The second discusses studies on Prospect theory, an alternative to Utility theory. The third focuses on empirical and theoretical studies of Under-reaction and Over-reaction. The fourth lumps other miscellaneous studies including individual investor behavior, applications of behavioral finance in corporate finance, etc.

\section{(a) Studies related to the Capital Asset Pricing Model}

The Capital Asset Pricing Model, derived empirically from the basic principles of traditional finance literature, was used initially to explain the return on risky assets, and also received some empirical support. However evidence as early as 1968 have shown that stocks with low P/E earn higher risk-adjusted returns vis$\dot{a}$-vis stocks with high $\mathrm{P} / \mathrm{E}$ [5]. Most of these early papers suffered severely from lack of robust methodology. Basu [6] was one of the first papers to receive wide recognition. He also found that stocks with low $\mathrm{P} / \mathrm{E}$ ratios gave higher risk-adjusted returns than those with high $\mathrm{P} / \mathrm{E}$ ratios. He argued that the observed anomaly was due to market inefficiency. However, this paper like many others suffered from the Joint Hypothesis problem. Their findings suggested that either Capital Asset Pricing Model or Efficient Market Hypothesis or both could be 
wrong.

Most of the above studies were also discredited by the proponents of EMH, owing to the presence of methodological errors. Ball [7] reviewed twenty studies of post-announcement excess returns including those on earnings announcements, dividends announcements, and value line ratings. He referred to these as proxies of yield and called them yield-surrogates. He concluded that methodological or data errors could not possibly explain all of the observed excess returns in these studies and concluded that the two-parameter model had few omitted variables related to yield surrogates. However, he failed to put forth a convincing argument as to why EMH was not invalid.

Later, Watts [8] provided an excellent argument against EMH. He conducted a two-period study and observed risk-adjusted abnormal returns in only one of the periods. Watts argued that if the risk-adjusted excess returns were due to model misspecification, then it should have been observed in both the periods. However, since the anomaly was observed in only one of the periods, Watts argued that it was probably because the market deviated from efficiency in that pe$\operatorname{riod}^{1}$.

The above studies clearly show that traditional theory is not inviolate in explaining market returns. From the Joint hypothesis problem either CAPM could be wrong or EMH or both. It should be noted, however, that while CAPM has been derived empirically from first principles of economics like Utility theory etc., EMH is just a hypothesis which has never been proven empirically beyond doubt.

\section{(b) Prospect theory}

The roots of most of the current asset pricing models like CAPM, APT etc. lie in the validity of Utility theory [10]. Kahneman \& Tversky [1] conducted several experimental studies and found evidence contrary to utility theory. They have shown experimental evidence for Certainty Effect, Reflection, Isolation effect etc., discussed in the next section, which contradicts Utility theory. Using the above anomalies as a basis, they proposed an alternative theory called the Prospect theory. Unlike utility theory, the decision-making process in Prospect theory is divided into two phases: the editing phase and the evaluation phase. The editing phase often results in simplification of prospects. Kahneman \& Tversky [1] refer to several biased editing techniques like Combination, Segregation, Coding etc. which people tend to use during the editing phase. These editing techniques can result in inferring wrong conclusions in the second phase. In the second stage the probabilities of prospects are replaced by decision weights and these decision weights in general are not necessarily equal to their respective probabilities. The Prospect theory value function is not always a concave function and is as shown in Figure 1.

Three decades since the first publication of the paper on Prospect theory, it is still one of the major contributions from behavioral finance questioning the validity of Utility theory. However, it is yet to achieve wide acceptance because

${ }^{1}$ See Jensen [9] for more on this literature. 


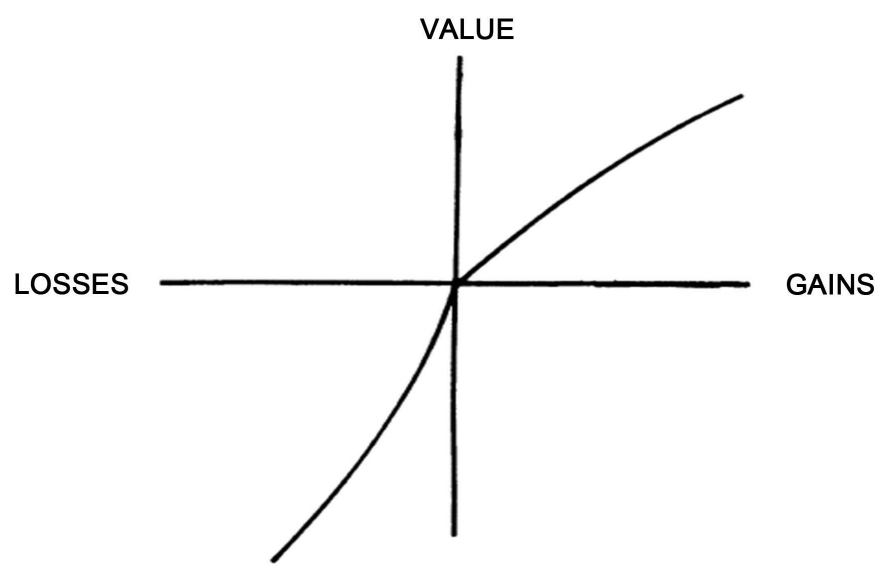

Figure 1. Prospect theory value function ${ }^{2}$.

unlike utility theory, Prospect theory is perhaps more complex. For example, it is possible for two similar persons with similar choices to choose different options depending on the way they simplify the options in the editing phase.

This value function represents the utility that is achieved as a result of a certain amount of gain or loss. The value function is an S-shaped curve. Similar to utility theory, at higher probability of gains it is concave in nature. However, it is convex when the probability of gains is very small. This shape derives from the testable hypothesis that people are risk averse when the probability of gain is large and positive, but risk seeking when the probability of gain is small and positive.

The reverse is the case for losses. When the probability of losses is large the value function is convex and when the probability of loss is very small it becomes concave. This implies that investors are risk seeking when the losses are large and risk averse when the losses are small. Also the value function of losses is much steeper than the value function of gains. This shows that a loss creates a greater feeling of having low value (pain) compared to the feeling of having higher value (joy) created by an equivalent gain. For example, people find it more painful losing $\$ 10$ than they feel joy in finding $\$ 10$.

\section{(c) Studies on Overreaction and Underreaction}

It is a well-documented fact in experimental psychology that people tend to overreact to sudden and unexpected news events. Bondt \& Thaler [11] tested this hypothesis in relevance to the stock market by testing if past losers outperform past winners. The logic behind this hypothesis is that investors tend to overreact to bad information in the previous quarters of a loser portfolio stock leading the stock to be more under-priced than it should optimally have been. Using a similar logic, stock in a winner portfolio should be over-priced. If the above hypothesis is correct, under-priced stocks should yield higher returns as the prices revert to their mean values and similarly overpriced stocks should give lower returns than expected. Their empirical results support this hypothesis and provide evidence for momentum in prices.

${ }^{2}$ Source: Kahneman, Daniel, \& Amos Tversky. 1979. "Prospect Theory: An Analysis of Decision under Risk.” Econometrica 47 (2): 263. doi: 10.2307/1914185. [1] 
The overreaction hypothesis discussed above can also be used to justify the $\mathrm{P} / \mathrm{E}$ anomaly discussed earlier. Stocks with low $\mathrm{P} / \mathrm{E}$ can be viewed as companies with bad information over the previous quarters. This negative information could have resulted in an overreaction by investors, leading to a larger drop in prices of stocks than rationally justifiable and hence low P/E. Similarly, stocks with high $\mathrm{P} / \mathrm{E}$ ratio can be viewed as overpriced stocks because of positive information over the previous quarters. Jegadeesh \& Titman [12] show that buying stock which have performed well and selling stocks which have performed badly over a 3 - 12 month holding period will generate excess profits. In a similar study Lakonishok, Shleifer, \& Vishny [13] prove that contrarian investment strategies generate risk-adjusted excess returns.

Fama \& French argued that except for Jegadeesh \& Titman's momentum strategy most of the above mentioned anomalies are due to missing factors in the pricing model and show that their three factor models account for most of the anomalies. However, the economic rationale given by them has received much criticism. $^{3}$

Combining the works of Jegadeesh \& Titman [12], who show short term momentum in stocks, with that of Fama \& French [3], and Bondt \& Thaler [11] who show long-term reversal in stocks, Barberis, Shleifer, \& Vishny [14] developed a model for explaining investor sentiment. Their model is based on the psychological concepts of representativeness and conservatism. Daniel, Hirshleifer, \& Subrahmanyam [15] also proposed a model for investor sentiment using concepts like overconfidence and biased self-attribution. Another important model of investor behavior explaining the above phenomenon is developed by Hong \& Stein [16].

(d) Miscellaneous

Shiller [17] showed that the stock prices are five to thirteen times more volatile than expected when compared to changes in dividends. However if EMH is true, the volatility of stock prices should be approximately equal to that of dividends. Even if we consider variations due to data errors, methodological errors etc the stock prices are too volatile to be explained by these.

One the common assumptions of EMH is that on an average noise traders bet against each other and at an aggregate level they don't have any effect on stock prices. Even if some of these noise traders try to influence the stock prices the rational speculators quickly act against them and remove any mispricing. However Long Shleifer Summers \& Waldmann [18] show that this would not hold true if noise traders follow positive feedback trading policies. They argue that it would be in the best interest of rational speculators to buy the stocks when they expect noise traders to buy stock so that they can sell it when the stock's price goes up. This line of reasoning implies that even rational agents acting rationally can lead to destabilization of markets.

\section{Psychological Concepts Used in Behavioural Finance}

Behavioural finance brings insights from psychology, cognitive science and other ${ }^{3}$ For example, see Daniel \& Titman [15]. 
social science disciplines to help us understand phenomenon which cannot be explained by traditional finance. This field encompasses similar and dissimilar theories that share one common factor. All question the sanctity of assumptions underlying EMH, and offer alternative explanations to explain observed behaviour. One of the main criticisms of this branch of research is that it is an ad hoc collection of several models each trying to explain a different phenomenon. As it lacks an overlaying principle which can explain all the observed anomalies, this area is ripe for further research. In this section, we describe some of the theories that are prevalent under this broad umbrella.

\section{(a) Disposition Effect}

The tendency of investors to sell winners too early and hold on to losers for too long is called Disposition Effect. In the process, people act as if they are trying to maximize their tax which is in contradiction to the predictions of traditional finance literature where people are tax minimizers. Ideally, people should book their losses early to gain tax benefits early and delay booking profits to defer paying taxes [19]. However, empirical evidence provides support for the Disposition Effect [20].

\section{(b) Cognitive Dissonance}

In Psychology, Cognitive Dissonance is defined as mental discomfort that people experience when they confront new information contradicting their existing views. People try to reduce dissonance by rejecting or misinterpreting any new information which is not in conformance with their existing beliefs. Cognitive Dissonance could be one of the reasons behind the delayed adjustment of stock prices for surprises in earnings announcements.

\section{(c) Regret Avoidance and Regret Theory}

Regret Avoidance deals with the emotional reaction people experience as humans have a tendency to feel the pain of regret for making errors in their judgment and tend to act in a way so as to reduce regret. Humans become emotionally affected by their original purchase price of a stock in their portfolio when they consider selling it. They avoid selling the stock in which they have made losses, in order to avoid the regret of having made a bad investment. This makes them hang on to a bad decision, which can further aggravate their loss. Similarly, people rush to book profits as soon as possible to reduce the pain of regret in future for not booking profits before the price falls from its peak [21]. Hence this tendency of humans to feel the pain of regret could be the reason behind the disposition effect. Similarly, cognitive dissonance can also be seen as a result of pain of regret of holding wrong views. So, people try to reduce the pain of regret by discrediting the new information and in turn try to reduce dissonance of holding wrong beliefs.

Regret Theory holds that people anticipate the regret they are going to have in making their financial decisions which can make them either risk seeking or risk averse. An investor may take greater risk to avoid the regret of not holding a security which has the potential to gain in future. Similarly, an investor may also become risk averse to avoid the regret of holding a stock which can perform 
poorly in future. The essence of Regret Theory is that Regret Avoidance can sometimes lead investors to make decisions which may reduce their regret in the short term but are likely to be inefficient in the long run.

(d) Anchoring Bias

It is a well-known fact that people make their final estimates by making adjustments to initial estimates. In psychology, these initial estimates are anchors. However, more often than not these adjustments are not sufficient enough to adjust the initial estimates. The resulting bias in the usage of anchors is called the Anchoring Bias. For example, past prices of stocks can act as anchors for investors.

(e) Representativeness

Representativeness is an important heuristic which can lead to biased decisions when making judgments on the probability of occurrence of event under uncertainty. A person whose decisions are biased by this heuristic evaluates the probability of an uncertain event "by the degree to which it is 1) similar in its essential properties to the parent population, and, 2) reflects the salient features of the process by which it is generated" [22]. For example, let us take a person who is acquainted with several Investment bankers who have a 16 hours/day work schedule. Now he suddenly comes across a person who has a 16 hours/day work schedule and isn't aware of any other characteristic of that person. He would immediately relate this person to his Investment banker acquaintances and mentally associates a high probability of him being an Investment Banker. However, in reality, less than $1 \%$ of the total population are investment bankers, and hence the probability of him being an Investment Banker is very low. This bias in judging an event based on how similar it is to its parent population is called representativeness.

\section{(f) Conservatism}

As the name suggests, Conservatism refers to the fact that people are sometimes conservative to new information i.e. people are slow in changing their beliefs to new information when compared to a rational Bayesian benchmark. Conservatism could be one of the reasons behind the underreaction to new information.

Even though several psychological theories have been explained here as if they are mutually exclusive in practice they are interlinked with one another. For example, the Disposition Effect can be explained as a special case of Regret avoidance. Similarly, Cognitive Dissonance can be seen as the pain of regret of mistaken beliefs. Market under and over reaction can be explained using investor overconfidence and self-attribution; representativeness bias and conservatism etc. Therefore, typically every anomaly observed through empirical studies can be explained by more than one of these theories. More research is required to study whether there are cases where these theories can be differentiated. ${ }^{4}$

${ }^{4}$ The above should not be viewed as a comprehensive listing of theories, rather as an analytical categorisation of main strands in the literature. See also Tversky \& Kahneman [23], Kahneman \& Tversky [1], and Shiller [21]. 


\section{Experimental Test of Prospect Theory}

Much of traditional finance theory is based on the assumption of the validity of utility theory including Capital Asset Pricing Model and Arbitrage theory of asset pricing. Kahneman \& Tversky [1] criticized some of the assumptions of Expected Utility theory and proposed an alternative called Prospect theory. This theory is developed from certain psychological concepts explained next.

One fair criticism of experimental research is that they use university students as human subjects. However trained professional might not be subjected to the same biases. Therefore we test Prospect theory by Kahneman \& Tversky [1] on officers from Indian Statistical services to see if they exhibit similar biases. Our subjects are also significantly much older than the experimental subjects of Kahneman \& Tversky [1]. Appendix I has the questionnaire administered to the subjects.

\section{i) Certainty Effect}

Certainty effect refers to the fact that people prefer certain outcomes to merely probabilistic outcomes. Kahneman \& Tversky [1] explain this phenomenon using the following pair of choice problems.

\begin{tabular}{ccc}
\hline Problem 1: & A : $(25,000,0.33 ; 24,000,0.66)$ & B: $(24,000,1.00)$ \\
\hline $17 \%$ & $83 \%$ \\
\hline Problem 2: & A: $(25,000,0.33)$ & B: $(24,000,0.34)$ \\
\hline & $50 \%$ & $50 \%$ \\
\hline
\end{tabular}

Source: Author's calculations.

[ Where notation $(25,000,0.33 ; 24,000,0.66)$ represents chance of winning 25,000 with 0.33 probability, 24,000 with 0.66 probability and zero with probability 0.01. Similarly $(25,000,0.33)$ represents chance of winning 25,000 with 0.33 probability and 0 with 0.67 probability. The percentages represent the proportion of participants who chose the respective options.]

In problem 1 subjects preferred option $B$. This implies

$0.33 * \mathrm{U}(25,000)+0.66{ }^{*} \mathrm{U}(24,000)<\mathrm{U}(24,000)$ or

$0.33 * \mathrm{U}(25,000)<0.34 * \mathrm{U}(24,000)$

However in problem 2 subjects prefer option A which violates the above inequality and hence violate the substitution axiom of utility theory. According to the utility theory the subjects should have chosen either the former or latter option in both the experiments. This unwarranted surge in preference of subjects for certain outcomes is called the certainty effect. While statisticians in our experiment also exhibit certainty effect it is less than as predicted by Kahneman \& Tversky [1]. We also conduct a simpler version of the above experiment as shown below. Our results are qualitatively similar to the above pair of choice problems. In problem $3,82 \%$ prefer Rs 30,000 with certainty $(p=1)$, and $18 \%$ prefer Rs 40,000 with 0.80 probability. In problem $4,52 \%$ prefer 30,000 with 0.25 probability and $48 \%$ prefer Rs 40,000 with 0.20 probability. From problem 3 and 
4 we can conclude that Statisticians exhibit much lesser certainty effect than as compared to students.

\begin{tabular}{ccc}
\hline Problem 3: & A : $(40,000,0.8)$ & B: $(30,000,1.00)$ \\
\hline $18 \%$ & $82 \%$ \\
\hline Problem 4: & A: $(40,000,0.20)$ & B: $(30,000,0.25)$ \\
\hline $48 \%$ & $52 \%$ \\
\hline
\end{tabular}

Source: Author's calculations.

In the same study, Kahneman \& Tversky [1] found that when the probability of winning is very low, then the subjects chose the option with a maximum possible payoff.

\begin{tabular}{ccc}
\hline Problem 5: & A: $(60,000,0.45)$ & B: $(30,000,0.9)$ \\
\hline $21 \%$ & $79 \%$ \\
\hline Problem 6: & A: $(60,000,0.001)$ & B: $(30,000,0.002)$ \\
\hline $52 \%$ & $48 \%$ \\
\hline
\end{tabular}

Source: Author's calculations.

In problem $5,79 \%$ prefer Rs 30,000 with 0.90 probability while $21 \%$ prefer Rs 60,000 with 0.45 probability. In problem 6, 48\% prefer Rs 30,000 with 0.002 probability while $52 \%$ prefer Rs 60,000 with 0.001 probability. In the above experiment we find when the probability of winning is very low people switch to the riskiest choice. However, the subjects would have chosen the same option in both the cases had expected utility theory held. We find that statistical officers do not change their preference at low probabilities to the extent predicted by Kahneman \& Tversky.

ii) Reflection Effect

In another set of experiments, Kahneman \& Tversky [1] showed that when their subjects were given an option between a risk averse and risky choice with equal expected gains, they chose the former. However, when the amounts were merely multiplied with a negative sign (loss expectation instead of profit), they chose the latter. This implies that people are risk averse as predicted by utility theory when it comes to profits while the same doesn't hold true when it comes to losses. This distortion in expected behavior of subjects when it comes to choices involving losses is called the reflection effect. Our results shown below for statisticians show that they also exhibit reflection effect.

\begin{tabular}{ccc}
\hline Problem 7: & A: $(-40,000,0.20)$ & B: $(-30,000,1.00)$ \\
\hline $80 \%$ & $20 \%$ \\
\hline Problem 8: & & \\
\hline & A: $(-40,000,0.20)$ & B: $(-30,000,0.25)$ \\
\hline
\end{tabular}




\begin{tabular}{ccc}
\hline Problem 9: & A $:(-60,000,0.45)$ & B: $(-30,000,0.9)$ \\
\hline $61 \%$ & $39 \%$ \\
\hline Problem 10: & A: $(-60,000,0.001)$ & B: $(-30,000,0.002)$ \\
\hline & $41 \%$ & $59 \%$ \\
\hline
\end{tabular}

Source: Author's calculations.

\section{iii) Isolation Effect}

When people are faced with two choices they generally tend to neglect commonalities between the two choices and focus only on the differences. For example, let us consider a two stage game where there is a $75 \%$ probability of ending the game with a zero payoff and $25 \%$ probability of moving to the second round. If you reach the second round you have a choice between the following options below. However the choice must be made before the outcome of first experiment is known.

\begin{tabular}{|c|c|c|}
\hline Problem 11: & $\mathrm{A}:(40,000,0.80)$ & B: $(30,000)$ \\
\hline & $30 \%$ & $70 \%$ \\
\hline
\end{tabular}

Source: Author's calculations.

This is similar to a one stage game of choosing between lotteries worth 40,000 with $20 \%(0.25 * 0.80=0.20)$ chance of winning and 30,000 with $25 \%(1 * 0.25=$ 0.25 ) chance of winning. However in the two stages game majority of the subjects chose option B while in the single stage game majority chose option A. This tendency of people to neglect commonalities between choices before making decisions can lead to making choices contradicting utility theory. This is called the isolation effect.

Coding: Coding refers to the fact that people make decisions perceiving individual outcomes as gains or losses rather than changes of their final state of wealth. This is in contradiction to the utility theory where it assumes people try to maximize the utility of their total wealth rather than the utility of individual decisions.

Using the above discussed psychological biases Kahneman \& Tversky [1] proposed the famed Prospect Theory discussed in the previous Section III.

\section{Discussion and Conclusion}

Many researchers have argued that the inability of empirical tests to reject EMH does not provide evidence in favor of the hypothesis. ${ }^{5}$ Researchers have different opinions on this issue. While the proponents of the Efficient Market Hypothesis believe that markets are efficient, the proponents of Behavioural finance believe that markets are inefficient intermittently. Even if the observed anomalies were a result of data mining and methodological errors, as the proponents of Efficient Market Hypothesis argue, we believe that these anomalies have led to a devel- 
opment of alternative hypothesis that has improved our understanding of the markets.

Since behavioural finance is a relatively new field, much of research has focussed on identifying anomalies. Now it is time to shift the focus of research in designing an overlaying principle which can explain multiple anomalies at a time. Lack of an alternative overlaying principle is also an important reason why people are reluctant to reject the Efficient Market Hypothesis. Barberis, Shleifer, \& Vishny [14]; Daniel, Hirshleifer, \& Subrahmanyam [15]; and Hong \& Stein [16] have made few attempts in developing empirical models which can simultaneously explain multiple phenomenon. Clearly much more effort is needed in this direction.

In this paper, we have discussed some of the foundational papers which have led to the development of behavioural finance. While much of the traditional finance literature is based on the assumption of validity of expected utility theory, it fails when tested empirically. Kahneman \& Tversky [1] proposed an alternative to Expected Utility theory for decision making under risk and called it Prospect Theory. Like many academic studies Kahneman \& Tversky [1] use student subjects in their experiments. Therefore we test if statistically trained subjects also exhibit the biases as proposed in Prospect theory. We find that our results are qualitatively similar but they are not as strong as predicted by Kahneman \& Tversky [1]. Therefore we conclude that experience helps in reducing the biases a lay person exhibits. With Prospect Theory finding extensive usage in behavioural finance literature [24], such experimental studies with diverse groups would go a long way in informing us whether Prospect Theory itself exhibits anomalies, or it can serve as a useful counterpoint to traditional finance. It would be interesting to see how these results will hold up if we carry out similar experiments on senior level management personnel of companies who actually affect the investment decisions. We leave this as an area of further research.

\section{Acknowledgements}

The authors are grateful to the Indian Institute of Management Calcutta for a Research Project Grant for financial support.

\section{References}

[1] Kahneman, D. and Tversky, A. (1979) Prospect Theory: An Analysis of Decision under Risk. Econometrica, 47, 263-292. https://doi.org/10.2307/1914185

[2] Shleifer, A. and Vishny, R.W. (1997) The Limits of Arbitrage. The Journal of Finance, 52, 35-55. https://doi.org/10.1111/j.1540-6261.1997.tb03807.x

[3] Fama, E.F. (1970) Efficient Capital Markets: A Review of Theory and Empirical Work. The Journal of Finance, 25, 383-417. https://doi.org/10.2307/2325486

[4] Niederhoffer, V. and Osborne, M.F.M. (1966) Market Making and Reversal on the Stock Exchange. Journal of the American Statistical Association, 61, 897-916. https://doi.org/10.1080/01621459.1966.10482183

[5] Breen, W. (1968) Low Price-Earnings Ratios and Industry Relatives. Financial Analysts Journal, 24, 125-127. http://www.jstor.org/stable/4470381 
https://doi.org/10.2469/faj.v24.n4.125

[6] Basu, S. (1977) Investment Performance of Common Stocks in Relation to their Price-Earnings Ratios: A Test of the Efficient Market Hypothesis. The Journal of Finance, 32, 663-682. https://doi.org/10.1111/j.1540-6261.1977.tb01979.x

[7] Ball, R. (1978) Anomalies in Relationships between Securities' Yields and YieldSurrogates. Journal of Financial Economics, 6, 103-126. https://doi.org/10.1016/0304-405X(78)90026-0

[8] Watts, R.L. (1978) Systematic “Abnormal” Returns after Quarterly Earnings Announcements. Journal of Financial Economics, 6, 127-150.

https://doi.org/10.1016/0304-405X(78)90027-2

[9] Jensen, M.C. (1978) Some Anomalous Evidence Regarding Market Efficiency. Journal of Financial Economics, 6, 95-101. https://doi.org/10.1016/0304-405X(78)90025-9

[10] Roll, R. and Ross, S.A. (1980) An Empirical Investigation of the Arbitrage Pricing Theory. The Journal of Finance, 35, 1073. https://doi.org/10.1111/j.1540-6261.1980.tb02197.x

[11] Bondt, W. and Thaler, R.H. (1985) Does the Stock Market Overreact? The Journal of Finance, 40, 793-805. https://doi.org/10.1111/j.1540-6261.1985.tb05004.x

[12] Jegadeesh, N. and Titman, S. (1993) Returns to Buying Winners and Selling Losers: Implications for Stock Market Efficiency. The Journal of Finance, 48, 65-91. https://doi.org/10.1111/j.1540-6261.1993.tb04702.x

[13] Lakonishok, J., Shleifer, A. and Vishny, R.W. (1994) Contrarian Investment, Extrapolation, and Risk. The Journal of Finance, 49, 1541-1578. https://doi.org/10.1111/j.1540-6261.1994.tb04772.x

[14] Barberis, N., Shleifer, A. and Vishny, R.W. (1998) A Model of Investor Sentiment. Journal of Financial Economics, 49, 307-343. https://doi.org/10.1016/S0304-405X(98)00027-0

[15] Daniel, K., Hirshleifer, D. and Subrahmanyam, A. (1998) Investor Psychology and Security Market Under- and Overreactions. The Journal of Finance, 53, 1839-1885. https://doi.org/10.1111/0022-1082.00077

[16] Hong, H. and Stein, J.C. (1999) A Unified Theory of Underreaction, Momentum Trading, and Overreaction in Asset Markets. The Journal of Finance, 54, 2143-2184. https://doi.org/10.1111/0022-1082.00184

[17] Shiller, R.J. (1981) Do Stock Prices Move Too Much to Be Justified by Subsequent Changes in Dividends? The American Economic Review, 71, 421-436. http://www.nber.org/papers/w0456

[18] Long, J.B., Shleifer, A., Summers, L.H. and Waldmann, R.J. (1990) Positive Feedback Investment Strategies and Destabilizing Rational Speculation. The Journal of Finance, 45, 379-395. https://doi.org/10.1111/j.1540-6261.1990.tb03695.x

[19] Ritter, J.R. (2003) Behavioral Finance. Pacific-Basin Finance Journal, 11, 429-437. https://doi.org/10.1016/S0927-538X(03)00048-9

[20] Odean, T. (1998) Are Investors Reluctant to Realize Their Losses? The Journal of Finance, 53, 1775-1798. https://doi.org/10.1111/0022-1082.00072

[21] Shiller, R.J. (1998) Human Behavior and the Efficiency of the Financial System (Cowles Foundation No. 1172). http://cowles.econ.yale.edu/P/cd/d11b/d1172.pdf

[22] Kahneman, D. and Tversky, A. (1972) Subjective Probability: A Judgment of Representativeness. Cognitive Psychology, 3, 430-454. https://doi.org/10.1016/0010-0285(72)90016-3 
[23] Tversky, A. and Kahneman, D. (1974) Judgment under Uncertainty: Heuristics and Biases. Science (New York, N.Y.), 185, 1124-1131. https://doi.org/10.1126/science.185.4157.1124

[24] Silva, E.M. and Takimoto, L. (2017) How to Model Noise Traders Investors Using Prospect Theory. OALib, 4, e3567. https://doi.org/10.4236/oalib.1103567 


\section{Appendix I}

Problem 1: Choose between one of the lotteries given below A: Win 24,000 with $100 \%$ probability

B: Win 25,000 with 0.33 probability; 24000 with 0.66 probability; 0 with 0.01 probability

Problem 2: Choose between one of the lotteries given below

A: Win 25,000 with a probability of $0.33 ; 0$ with a probability of 0.67

B: Win 24,000 with a probability of 0.34 ; 0 with a probability of 0.66

Problem 3: Choose between one of the lotteries given below

A: Win 30,000 for sure

B: Win 40,000 with 0.80 probability; 0 with 0.20 probability

Problem 4: Choose between one of the lotteries given below.

A: Win 30,000 with 0.25 probability; 0 with 0.75 probability

B: Win 40,000 with 0.20 probability; 0 with 0.80 probability

Problem 5: Choose between one of the lotteries given below

A: Win 30,000 with a probability of $0.90 ; 0$ with a probability of 0.10

B: Win 60,000 with a probability of $0.45 ; 0$ with a probability of 0.55

Problem 6: Choose between one of the lotteries given below

A: Win 60,000 with a probability of $0.001 ; 0$ with a probability of 0.999

B: Win 30,000 with a probability of $0.002 ; 0$ with a probability of 0.998

Problem 7: Choose between one of the lotteries given below

A: Lose 40,000 with 0.80 probability; 0 with 0.20 probability

B: Lose 30,000 for sure

Problem 8: Choose between one of the lotteries given below

A: Lose 30,000 with 0.25 probability; 0 with 0.75 probability

B: Lose 40,000 with 0.20 probability; 0 with 0.80 probability

Problem 9: Choose between one of the lotteries given below

A: Lose 60,000 with 0.45 probability; 0 with 0.55 probability

B: Lose 30,000 with 0.90 probability; 0 with 0.10 probability

Problem 10: Choose between one of the lotteries given below

A: Lose 30,000 with 0.002 probability; 0 with 0.998 probability

B: Lose 60,000 with 0.001 probability; 0 with 0.999 probability

Problem 11: Let's consider a two stage game. In the first stage there is $75 \%$ probability you will be out of the game without winning anything while there is $25 \%$ probability that you will be promoted to the second stage. If in the second stage you have a choice between the following lotteries which one would you choose. You should make your choice before round one.

A: 30,000 for sure

B: Win 40,000 with 0.80 probability; 0 with 0.20 probability 
Submit or recommend next manuscript to SCIRP and we will provide best service for you:

Accepting pre-submission inquiries through Email, Facebook, LinkedIn, Twitter, etc. A wide selection of journals (inclusive of 9 subjects, more than 200 journals)

Providing 24-hour high-quality service

User-friendly online submission system

Fair and swift peer-review system

Efficient typesetting and proofreading procedure

Display of the result of downloads and visits, as well as the number of cited articles Maximum dissemination of your research work

Submit your manuscript at: http://papersubmission.scirp.org/

Or contact tel@scirp.org 